\title{
Efficiency of phytobiotics of Indian medicinal plant Tridax procumbens $L$. against wound infecting bacteria
}

\begin{abstract}
Many pathogenic bacteria are becoming increasingly resistant to many commonly used antibiotics including penicillins, macrolides and aminoglycosides. Hence in the present study efficacy of phytobiotics of Tridax procumbens (Linn) was assessed against the Escherichia coli, Staphylococcus aureus Streptococcus pyogens and Pseudomonas aeruginosa cultured from wound swab samples of 50 patients of diverse types of wounds. The crude extract of leaves of Tridax procumbens $L$. was used and compared with cephalosporin, amoxicillin and streptomycin as control. The results of antibacterial resistant profile of Tridax procumbens $L$. showed that there is an increase in the efficacy up to $16-24 \%$ for E.coli ; 9-18\% for Streptococcus pyogens and $15-30 \%$ for Pseudomonas aeruginosa. The results are on par with all selected antibiotics for Staphylococcus aureus. Hence it is recommended that an alternative to antibiotics are the phytobiotics of Tridax procumbens (Linn) for the rapid healing of wounds.
\end{abstract}

Keywords: phytobiotics, Tridax procumbens L., leaf extract, wound infection bacteria

\author{
Volume I Issue 6 - 2018
}

Yasodha T, Jeevitha, Yogesh, Ramanan

Department of Industrial Biotechnology, Shri Andal Alagar College of Engineering, India

Correspondence: Yasodha T, Department of Industria Biotechnology, Shri Andal Alagar College of Engineering, Kancheepuram, Tamilnadu, India, Tel 04427565662. Emailbtmbty@gmail.com

Received: October 31, 2018 | Published: December 26, 2018

\section{Introduction}

Widespread antibiotic usage exerts a selective pressure that acts as a driving force in the development of antibiotic resistance. The association between increased rates of antimicrobial use and resistance has been documented for nosocomial infections as well as for resistant community acquired infections. ${ }^{1,2}$ As resistance develops to "firstline" antibiotics, therapy with new, broader spectrum, more expensive antibiotics increases, but is followed by development of resistance to the new class of drugs. ${ }^{3}$ An alternative to antibiotics are the phytobiotics which can be used as potential resource in the treatment of infected wounds. Tridax procumbens Linn (Tridax) is commonly known as coat buttons' in English because of the appearance of its flowers and in Tamil Vettukkaaya thalai. It has been extensively used in ayurvedic system of medicine. It is a wild herb distributed throughout India. The leaf extract possesses antiseptic, insecticidal and anti parasitic properties. It is also used to check haemorrhage from cuts, bruises and wounds. The use of plants and plant bioactive compounds dates back thousands of years to the ancient Egyptians, Chinese, Indians and Greeks. ${ }^{4,5}$ Indian herbal medicines have been used for many centuries for treating various human diseases. ${ }^{4,6-8}$

Herbal medicines are well known for its fast remedy and cheap source of availability. Several Indian medicinal weeds are popular for its medicinal value in healing wounds and treating other ailments. Recent studies also impart the identification and isolation of new therapeutic compounds of medicinal importance from the higher plants for specific diseases. Natural products from higher plants may contribute to the search for new drugs by indicating new modes of pharmacological action. Hence the present study is focused to determine the pharmacological role of leaf extracts of Tridax procumbens against the wound infecting bacteria such as E.coli, Staphylococcus aureus, Streptococcus pyogens and Pseudomonas aeruginosa. Phytobiotic resistance profile was compared with cephalosporin, amoxicillin and streptomycin.

\section{Materials and methods}

The leaves of Tridax procumbens (Linn) collected from various areas of Namakkal District were crushed and extract was taken in sterilized petri dishes. Air dried crude extract powder of Tridax biotics was taken in different concentrations of $0.2,0.4,0.6,0.8$ and $1 \mathrm{mg}$ for the study. The antibacterial activity of the extracts was analyzed and compared with the standard antibiotics Cephalosporin, Streptomycin and Amoxicillin.

\section{Collection of microbes}

Bacterial strains such as Escherichia coli, Streptococcus pyogens Pesudomonas aeruginosa, Staphylococcus aureus were isolated from diverse wounds of 50 patients which were collected on cotton swabs. The isolated microbes were maintained in Nutrient agar Broth and cultured in Nutrient Agar medium.

\section{Preparation of medium and inoculum}

Nutrient agar medium was prepared by dissolving $2.8 \mathrm{~g}$ of nutrient agar in $100 \mathrm{ml}$ of distilled water. The solution was sterilized in an autoclave at $121^{\circ} \mathrm{C}$ for $15 \mathrm{~min}$. It was cooled and poured into sterile Petri dishes to solidify. Each wound infecting bacterium is inoculated on agar by streaking with the swab containing inoculums. Rotate the plate by $60^{\circ}$ and repeat the rubbing procedure. This will ensure an even distribution of the inoculums.

\section{Disc diffusion method}

Antibiotic discs were kept on the surface of the inoculated plates. The Tridax biotic disc was prepared by dipping the $6 \mathrm{~mm}$ Whatman No1 Filter paper in the 0.2, 0.4, 0.6, 0.8 and $1 \mathrm{mg}$ aqua extract of Tridax. Phytobiotic discs were kept in the incubator for complete drying. Maximum of 5 discs were kept in the petriplate.

\section{Results and discussion}

Results for concentrations $0.2,0.4,0.6,0.8$ and $1 \mathrm{mg}$ Tridax biotics and the same concentrations of standard antibiotics act on wound infecting bacteria were recorded with reference to the zone of inhibition in $\mathrm{cm}$. (Table $1 \&$ Figures $1-4$ ). The result was found to be most effective against all tested microorganisms. Maximum inhibition concentration of phytobiotics is 0.8 to $1 \mathrm{mg}$ which is effective against all wound infecting bacteria (Figure 1-4). The results pertaining to the 
antibiotic activity of Tridax procumbens Linn (leaf extract) against the wound infecting pathogen Staphylococcus aureus is on par with the selected antibiotics. The infected wounds containing bacterial pathogens such as, Staphylococcus aureus, Streptococcus pyogens, Pesudomonas aeruginosa and Escherichia coli were treated with phytobiotics of Tridax showed the maximum zone of inhibition (ZOI) as follows $2.1>2.2>2.3>2.5(\mathrm{~cm})$ Escherichia coli was controlled by the antibiotics from the range 1.9 to $2.1 \mathrm{~cm}$ as maximum zone of inhibition, where as the concentration of $0.4 \mathrm{mg}$ phytobiotics of Tridax showed maximum zone of inhibition up to $2.5 \mathrm{~cm}$. Next to Escherichia coli, Pesudomonas aeruginosa was controlled maximum by Tridax biotics .This was confirmed in terms of $2.3 \mathrm{~cm}$ zone of inhibition. The maximum zone of inhibition for Staphylococcus aureus and Streptococcus pyogens was $2.1 \mathrm{~cm}$ and $2.2 \mathrm{~cm}$ respectively. Similar kind of experimental results of, ${ }^{9-11}$ showed the efficacy of bioactive compounds of various herbal medicinal plants against infectious pathogens.

Table I Effect of Tridax procumbens against wound infection bacteria (Diameter of inhibition zone in $\mathrm{cm}$ )

\begin{tabular}{lllll}
\hline $\begin{array}{l}\text { Antibiotics \& } \\
\text { phytobiotics }\end{array}$ & E.coli & $\begin{array}{l}\text { Staphylococcus } \\
\text { aureus }\end{array}$ & $\begin{array}{l}\text { Streptococcus } \\
\text { pyogens }\end{array}$ & $\begin{array}{l}\text { Pseudomonas } \\
\text { aeruginosa }\end{array}$ \\
\hline Cephalosporin & 2.1 & 1.9 & 1.8 & 1.8 \\
Streptomycin & 2 & 2.1 & 2.3 & 2 \\
Amoxicillin & 1.9 & 2 & 2 & 2.1 \\
Tridax biotics & 2.5 & 2.1 & 2.2 & 2.3 \\
\hline
\end{tabular}

*Results are expressed as the mean value of triplicates.

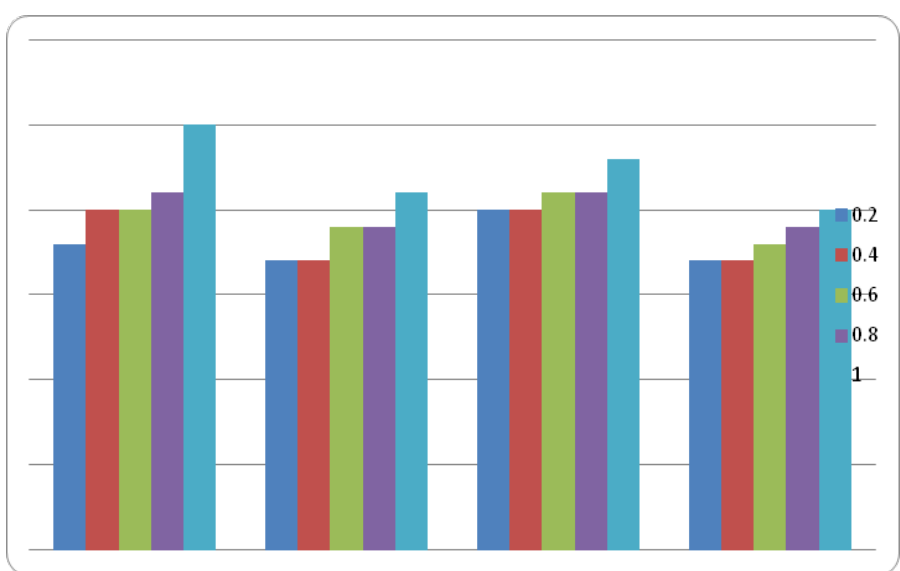

Figure I Antibiotic and Tridax biotics resistance Profile for E.coli (concentration in $\mathrm{mgVs}$ zone of inhibition in $\mathrm{cm}$ ).

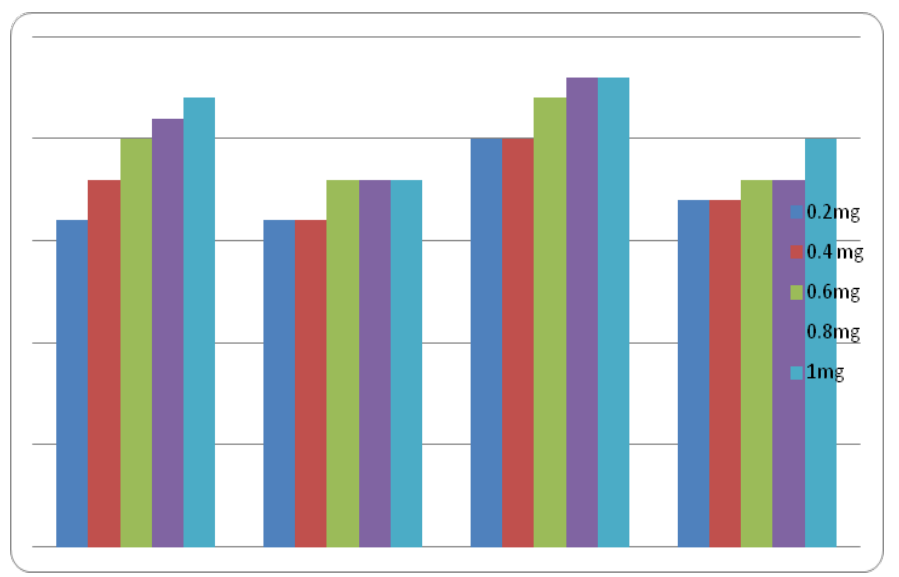

Figure 2 Antibiotic and Tridax biotic resistance Profile for S.pyogens (concentration in $\mathrm{mgVs}$ zone of inhibition in $\mathrm{cm}$ ).

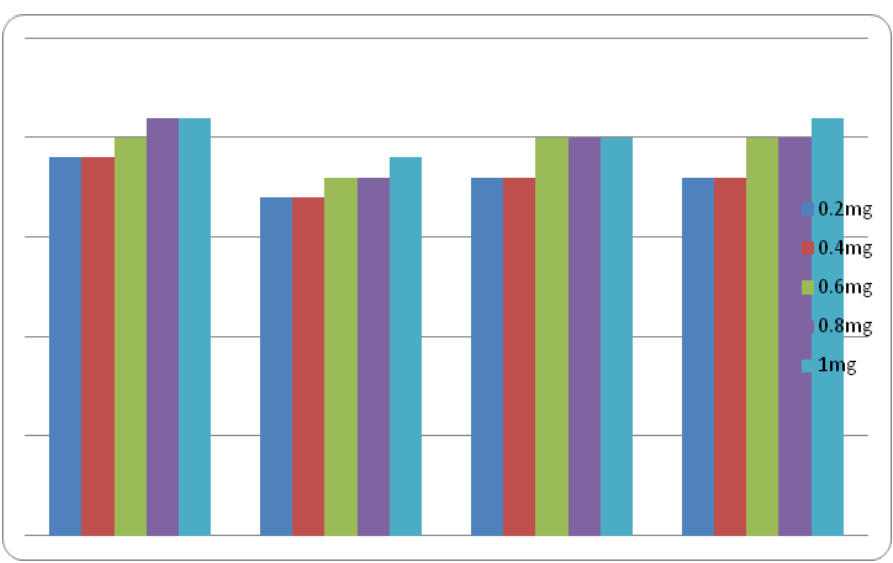

Figure 3 Antibiotic and Tridax biotic resistance Profile for S.aureus (concentration in $\mathrm{mg}$ Vs zone of inhibition in $\mathrm{cm}$ ).

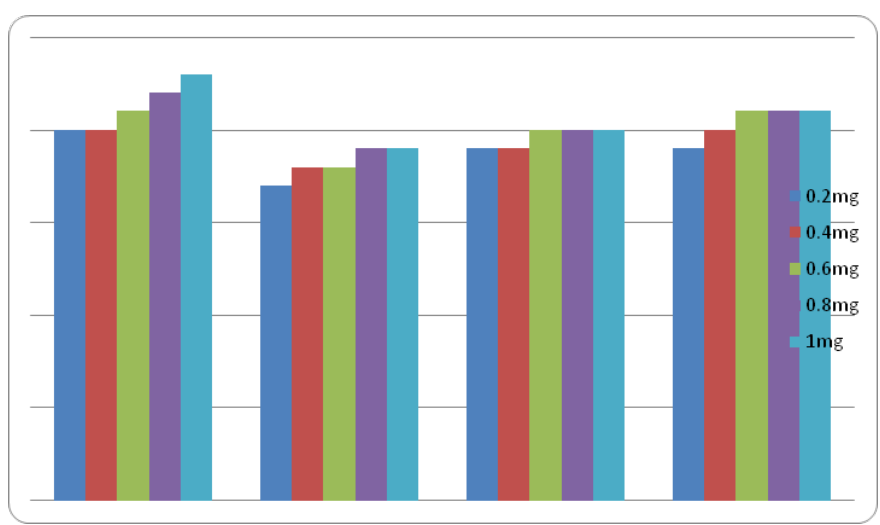

Figure 4 Antibiotic and Tridax biotic resistance Profile for P.aeruginosa (concentration in $\mathrm{mgVs}$ zone of inhibition in $\mathrm{cm}$ ).

\section{Conclusion}

The response of wound infection pathogenic bacteria for the 
Tridax biotics are in the following order:

Staphylococcus aureus $>$ Streptococcus pyogens >Pesudomonas aeruginosa $>$ Escherichia coli

From the present investigation of resistance profile of wound infection causing bacteria, it is suggested that usage of antibiotics could be reduced by the proper dosage of phytobiotics. Hence the Tridax biotics can be used as potential resource in the treatment of infected wounds. ${ }^{12,13}$

\section{Acknowledgments}

None.

\section{Conflicts of interest}

The authors declare that there is no conflict of interest.

\section{References}

1. Brown OD, Izundu A. Antibiotic resistance in clinical isolates of Pseudomonas aeruginosa in Jamaica. Rev Panam Salud Publica. 2004;16(2):125-30.

2. Bayat M, Zia M, Haghi M, et al. Antibiotic resistance pattern of Escherichia coli, staphylococcus aureus and Pseudomonas aeruginosa isolated from burnt patients in Urmia, Iran. African Journal of Microbiology Research. 2011;5(9):996-1000.

3. Landis SJ. Chronic wound infection and antimicrobial use. Adv Skin \& wound care. 2008;21(11):531-540.

4. Grizard D, Barthomeuf C. Non-digestible oligosaccharides used as prebiotic agents: mode of production and beneficial effects on animal and human health. Reproduction Nutrition Development. 1999;39(5-6)563588.
5. Cherbut C, Michel C, Raison V, et al. Acacia gum is a bifidogenic dietary fibre with high digestive tolerance in healthy humans. Microbial Ecology in Health and Disease. 2003;15:43-50.

6. Aniel KO, Naidu ML. Antibacterial potential of Tridax procumbens L. against human pathogens. International Journal of Pharmaceutical Sciences. 2011;2 (2):21-30.

7. Ankita J, Jain A. Tridax procumbens (L): A weed with immense medicinal importance: A review. International Journal of Pharma and Biosciences. 2012;3: 544-547.

8. Ayyanar M. Indian medicinal plants as a source of therapeutic agents: A review. International Journal of Bioscience Research. 2012;1(1):1-23.

9. Srinivasan D, Perumalsamy LP, Nathan S, et al. Antimicrobial activity of certain Indian medicinal plants used in folkloric medicine. J Ethnopharm. 2001;74(3):217-222.

10. Mohamed Sham Shihabudeen H, Hansi Priscilla D, Kavitha T Antimicrobial activity and Phytochemical analysis of selected Indian folk medicinal plants. Int J of Pharma Sci Res. 2010;1:430-434.

11. Sarita Das, Janaki Kumari Padhy, Pritilata Panda. Bioactive potential of Tridax procumbens L. leaf extract against skin infection causing bacteria. International Journal of Herbal Medicine. 2017.5(3):127-133.

12. Ali M, Ravinder E, Ramachandran R. Anticoagulant activity of Tridax procumbens. Fitoterapia. 2001;72:313-315.

13. Dhanabalan R, Doss A, Jagadeeswari M. In vitro phytochemical screening and antibacterial activity of aqueous and methanolic leaf extracts of Tridax procumbens. 2008;(1). 